\title{
A Systematic Review of the World of Validated Suprapubic Catheter Insertion Simulation Trainers: From ‘Head-Blocks' to 'Lunch Boxes'
}

\author{
James Nonde $^{\mathrm{a}}$ Abdullah Ebrahim Laher ${ }^{\mathrm{a}} \quad$ Jared McDowall $^{\mathrm{a}} \quad$ Ahmed Adam $^{\mathrm{b}}$ \\ ${ }^{a}$ Division of Emergency Medicine, Faculty of Health Sciences; 'bivision of Urology, Department of Surgery, University of the Witwatersrand, \\ Johannesburg, South Africa
}

\author{
Key Words \\ Validated • Suprapubic catheter insertion • Trainer models • \\ Simulators $\cdot$ Simulation
}

\begin{abstract}
Purpose: Various suprapubic catheter insertion simulators have been described to aid in the training of this fundamental skill. The purpose of this review was to evaluate and critically appraise all validated simulators. Methods: The PubMed, Web of Science, Cochrane Library, Scopus, British Medical Journal and the Embase databases were searched (March 2018), by using key search terms "suprapubic trainer", "suprapubic model", "suprapubic simulation" and "suprapubic simulator". Results: A total of 196 articles were identified; 117 unrelated, 53 animal studies and 20 duplications. Only 6 articles met the inclusion criteria for this review. The median number of participants per study was 30.5. Material costs ranged from 1.71 to 60 dollars per model. Only 2 studies incorporated the use of ultrasound. Conclusion: Despite validated suprapubic catheter insertion models being a specially needed learning resource, only few have been described-mostly for not resourceful environments.
\end{abstract}

\section{KARGER}

Fax +4161306 1234

E-Mail karger@karger.com

www.karger.com
(C) 2020 The Author(s)

Open access

This article is licensed under the Creative Commons AttributionNonCommercial-NoDerivatives 4.0 International License (CC BYNC-ND) (http://www.karger.com/Services/OpenAccessLicense) Usage and distribution for commercial purposes as well as any distribution of modified material requires written permission.
There exists a general lack of guidelines on model validation processes. There is a need to develop, appropriately validate and integrate models into training curriculum.

(c) 2020 The Author(s)

Published by S. Karger AG, Basel

\section{Introduction}

Percutaneous suprapubic catheter (SPC) insertion is a vital skill that urologists and emergency department physicians need to perform proficiently to avoid the morbidity and mortality that may arise from this procedure $[1,2]$. Indications for SPC placement include urethral injuries, urethral strictures, bladder neck masses, benign prostatic hyperplasia and occasionally, prostate cancer [1]. The absence of an easily palpable or ultrasonographically localized distended urine bladder is an absolute contraindication to SPC insertion $[1,2]$.

Training in invasive surgical procedures continues to shift from the Sir William Halsted apprenticeship model of 'see one, do one, teach one' to that of simulation-based medical education (SBME), permitting the safe repeti- 
Table 1. Details of CASP tool used to assess the studies included for review

\begin{tabular}{|c|c|c|c|c|c|c|c|}
\hline & \multirow[t]{2}{*}{ Questions } & \multicolumn{5}{|c|}{ Authors } & \multirow[b]{2}{*}{$\begin{array}{l}\text { Nonde } \\
\text { et al. [22] }\end{array}$} \\
\hline & & $\begin{array}{l}\text { Shergil } \\
\text { et al. [17] }\end{array}$ & $\begin{array}{l}\text { Hossack } \\
\text { et al. [18] }\end{array}$ & $\begin{array}{l}\text { Olapade-Olaopa } \\
\text { et al. [19] }\end{array}$ & $\begin{array}{l}\text { Singal } \\
\text { et al. [20] }\end{array}$ & $\begin{array}{l}\text { Palvogyi } \\
\text { et al. [21] }\end{array}$ & \\
\hline 1 & Did the study address a clearly focused issue? & yes & yes & yes & yes & yes & yes \\
\hline 2 & Was the cohort recruited in an acceptable way? & $\mathrm{CT}$ & $\mathrm{CT}$ & $\mathrm{CT}$ & $\mathrm{CT}$ & $\mathrm{CT}$ & $\mathrm{CT}$ \\
\hline 3 & Was the exposure accurately measured to minimize bias? & CT & CT & CT & CT & CT & CT \\
\hline 4 & Was the outcome accurately measured to minimize bias? & yes & CT & CT & yes & CT & yes \\
\hline $5 \mathrm{a}$ & Have the authors listed all confounding factors? & no & no & no & no & no & no \\
\hline $5 b$ & Have the authors taken account of all the confounding factors? & no & no & no & no & no & no \\
\hline $6 \mathrm{a}$ & Was the follow-up complete enough? & CT & CT & CT & CT & CT & CT \\
\hline $6 b$ & Was the follow-up long enough? & yes & no & yes & no & CT & no \\
\hline 7 & Do you believe the results? & yes & yes & yes & yes & yes & yes \\
\hline 8 & Can the results be applied to a local population? & yes & yes & yes & yes & yes & yes \\
\hline 9 & Do the results of the study fit with other available evidence? & yes & yes & yes & yes & yes & yes \\
\hline
\end{tabular}

$\mathrm{CT}=$ Cannot tell.

tive practice of skills or procedures [2,3]. This is aimed at ensuring that trainees have adequate time to perform and perfect a skill before it can be performed on real-life subjects [4]. SBME avoids compounding patients' safety by preventing patient exposure to the risks of the early part of the surgical learning curve, a period during which more surgical 'errors' are known to occur [2, 5].

SPC insertion is a relatively common procedure in the emergency department. Its complications include post-insertion gross hematuria $(2-16 \%)$, post-obstruction diuresis $(0.5-52 \%)$, post-bladder emptying hypotension, sepsis and intra-abdominal visceral injury [6]. SP$\mathrm{C}$-associated iatrogenic bowel injury is estimated to be at $2.4-2.7 \%$ with a 30 -day mortality rate of $1.8 \%[7,8]$.

The use of real-time ultrasound is associated with a lower risk of visceral injury compared to blind insertions. Evidence from studies and case reports supports the appropriate integration of ultrasound in both training curricular and real-life insertions so as to help localize the distended urinary bladder and avoid inadvertent visceral injury $[4,9,10]$. A successful SBME program requires the development and use of models that are supported by validation studies with good evidence [11].

Models with variant validities, costs, and real-life anatomy mimicking abilities have been described. An ideal surgical simulator is one that provides realistic experience and feedback that closely mimic real-life experiences [12].

Validity is a measure of the extent to which a simulator delivers a task it is meant to achieve [13]. This validation process can be subjective and/or objective. Subjective studies involve face, content, expert and referent types of validity which are mainly opinions of study participants. Objective studies aim to assess discriminative, construct and criterion ('concurrent' and 'predictive') validity [11]. Face validity examines the realism of a model while content validity evaluates its suitability for use as a training tool [13].

This review was aimed at evaluating and critically appraising all the currently published and validated SPC insertion simulators.

\section{Materials and Methods}

\section{Search Strategy}

A search strategy was developed and performed using electronic database search. The PubMed, Web of Science, Cochrane Library, Scopus, British Medical Journal and the Embase databases were searched (March 2018). The search terms: 'suprapubic catheter trainer', 'suprapubic catheter model', 'suprapubic catheter simulation' and 'suprapubic catheter simulator' were used. The citations of the papers generated by the search were also analyzed for any additional articles. Language restriction was not applied to this review.

\section{Study Selection/Eligibility Criteria}

Studies considered for inclusion met the following criteria: 1) the studies were clinical publications; 2) full text articles, and 3) studies provided details regarding positive versus negative findings. All published studies relating to the topic were eligible for inclusion. In the review process, animal studies/models were excluded.

\section{Data Extraction and Methodological Quality Evaluation}

The Preferred Reporting Items for Systematic Reviews and Meta-Analyses Protocols guidelines were adhered to during the review [14]. After the search, authors collectively assessed the 


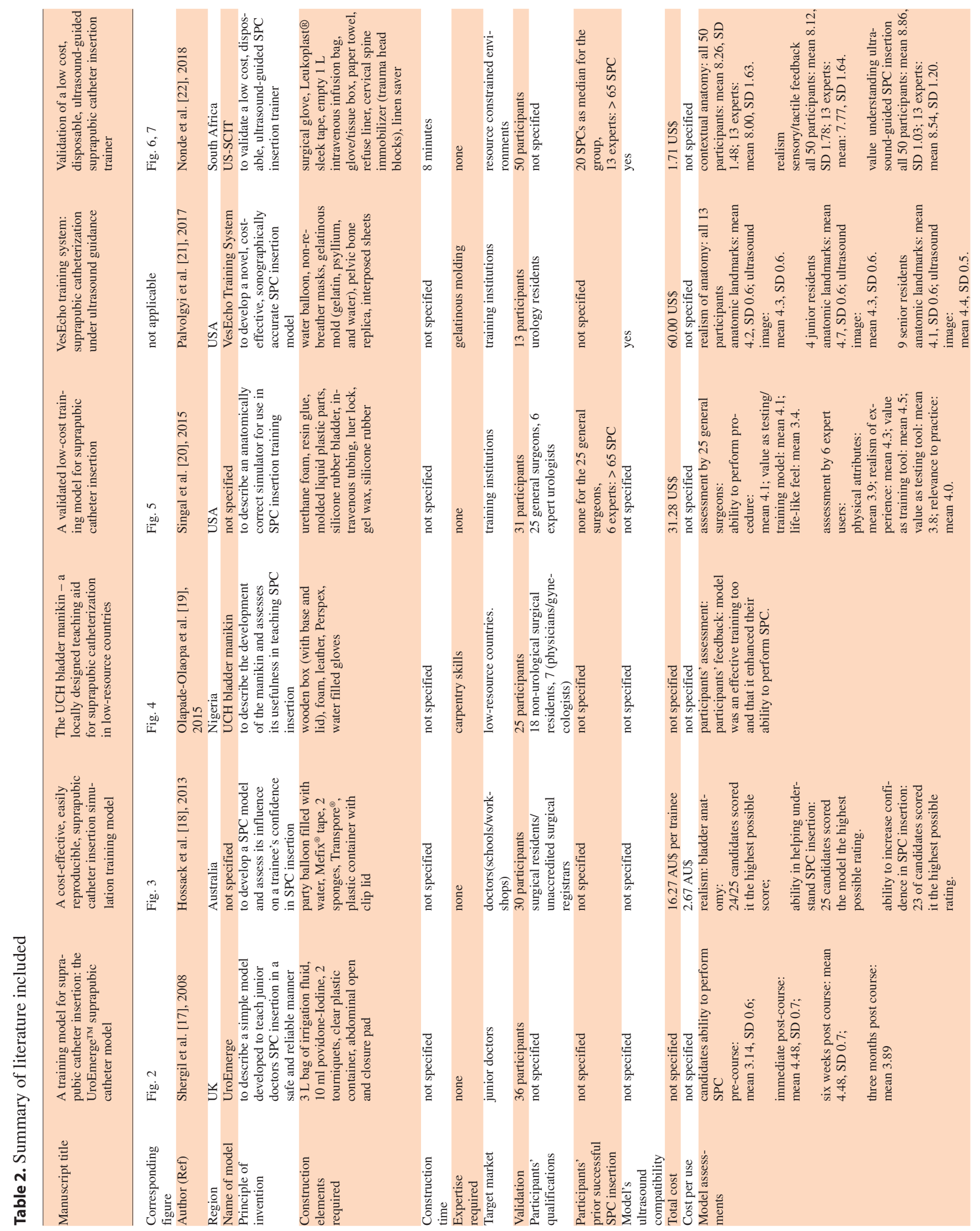




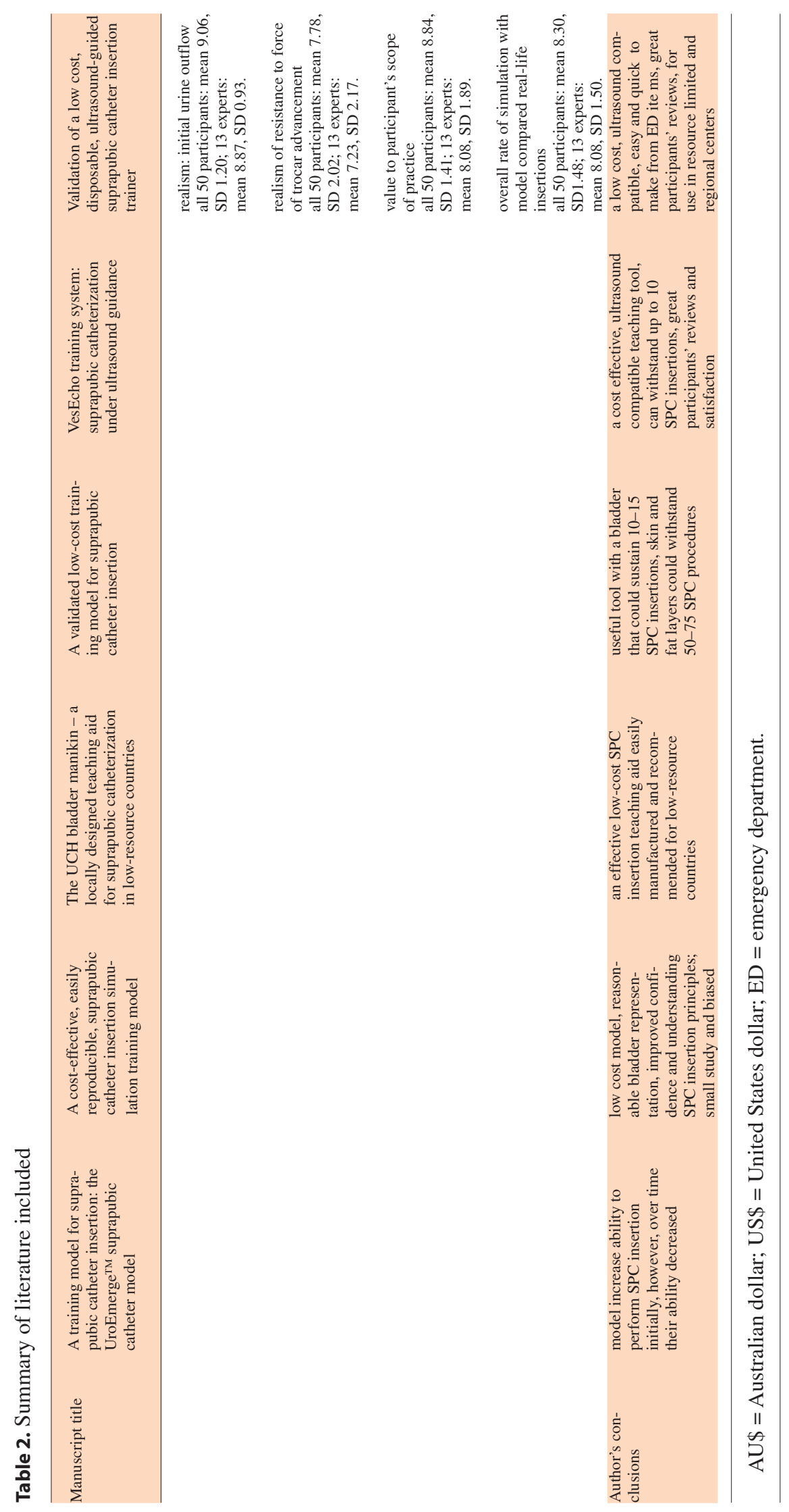




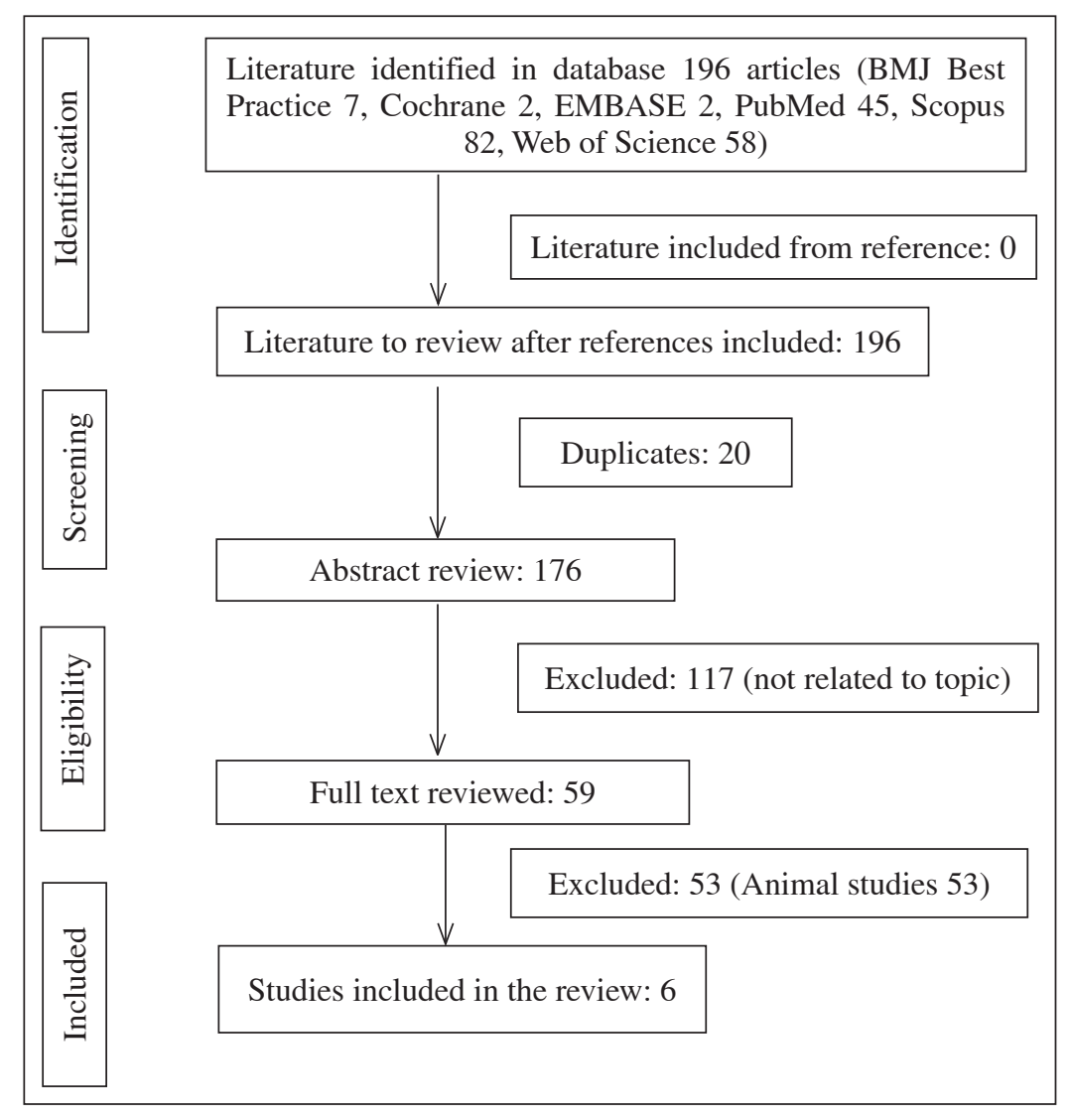

Fig. 1. Study flow diagram.

articles for the inclusion criteria. Selected studies were ranked for quality and relevance using the Critical Appraisal Skills Programme (table 1) [15]. Relevant studies were assessed based on the participants numbers, participants' qualifications, prior SPC insertion/s, ultrasound compatibility, model/material cost, cost per use, construction time, expertise and materials required for model construction (table 2).

Conflicting entries, disagreements and differences were resolved by consensus amongst all reviewers.

\section{Results}

\section{Search}

The search yielded 196 articles, represented as follows: British Medical Journal best practice $(n=7)$, Cochrane Database of Systematic Reviews $(\mathrm{n}=2)$, Embased $(\mathrm{n}=$ $2)$, PubMed $(n=45)$, Scopus $(n=82)$, and the Web of Science $(n=58)$ articles. The articles were screened for both duplicates and content. A total of 190 articles were excluded: 20 duplicates, 117 non-related articles and 53 animal studies. The researchers independently reviewed the remaining 6 articles that were included in the review (fig. 1).

\section{Participant Characteristics}

The number of study participants ranged 13-50 (median 30.5) per study. Four of the 6 studies (66.7\%) did not specify the participants' prior experience in SPC insertion [17-21]. In general, a greater number of participants had little to no prior experience. 'Expert assessors' (defined by $>65$ prior real-life successful SPC insertions) accounted for 19.35 and 26\% in Singal's and Nonde's studies respectively, thereby making an overall expert participation rate of only $10.27 \%$ [17-22].

\section{Model Construction Requirements}

The required materials were generally common readily available household materials and/or those found in most emergency departments, without the need of some 


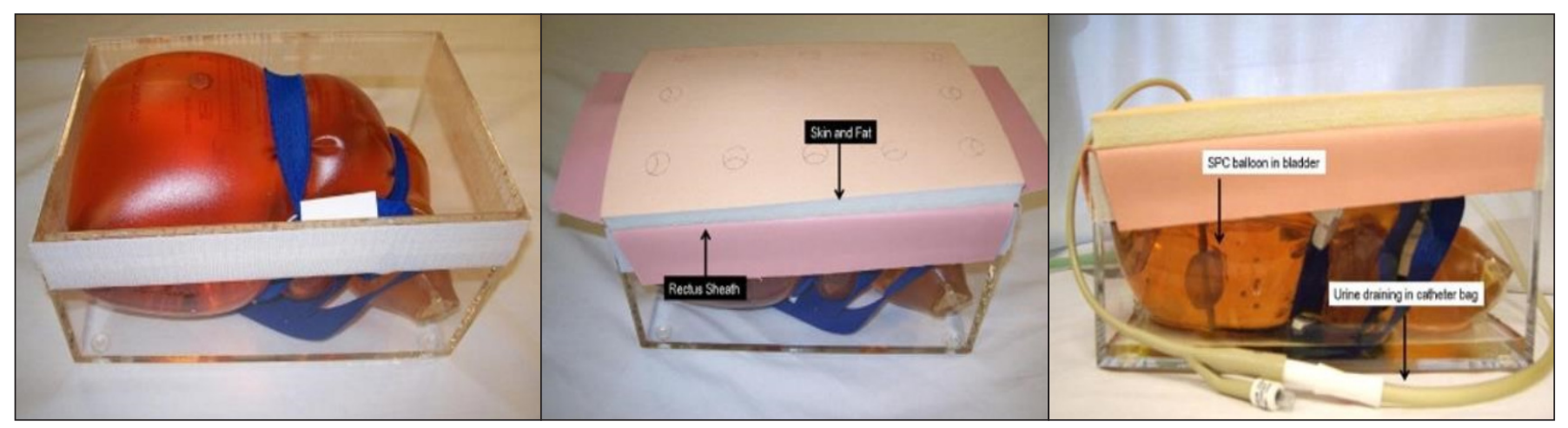

Fig. 2. The UroEmerge ${ }^{\mathrm{TM}}$ Suprapubic Catheter Model, Construction images (Image reproduced with courtesy of publisher: Elsevier, with permission certificate number: 4302050717055, date of certificate: Mar 04, 2018).

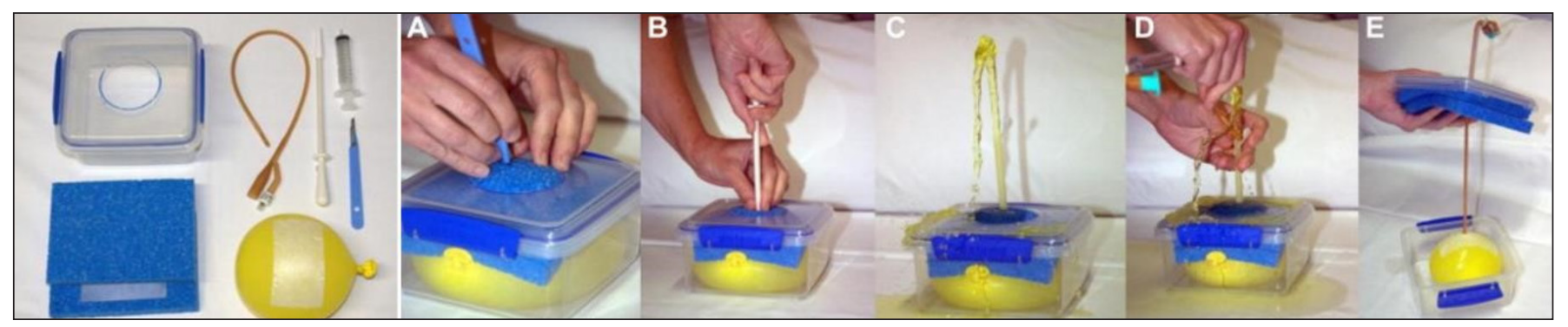

Fig. 3. The Hossack et al. Suprapubic Catheter Insertion Simulation Training Model Construction and simulation images (Image reproduced with courtesy of publisher: Elsevier, with permission certificate number: 4302051291270, date of certificate: Mar 04, 2018).

sort of expert handling (table 2). Some models were constructible from scratch within a few minutes while others require pre-made parts [17-22].

\section{Model Costs}

The cost of individual elements as well as the number of time they may be reused determined the estimated material cost. Some researchers clearly stated the costs while others simply overlooked it. The target market for most of the described models was tailored for low income settings [17-22].

\section{Ultrasound Compatibility}

The use of real-time ultrasound guidance was only assessed in 2 recent studies assessed [21, 22].

\section{Validity Assessed}

All studies assessed face, content, expert and/or referent types of validity, which were the opinions of the participants [17-22].

\section{Discussion}

Simulation training has been a main feature of the aviation industry as part of the prerequisites for pilots to be certified safe to fly [16]. Taking a leaf out of this approach, the field of medicine continues to embrace and integrate the use of SBME. The development, validation and appropriate curricular integration of SPC insertion training models are a great example of this ever expanding endeavor.

At the time of this review, 6 models had been described and validated [17-22]. There was a general lack of consensus guidelines on how validation studies should be conducted. Standardized definition of terms such as an 'expert user' and their appropriateness to assess the models remains debatable. The 6 studies mainly explored face and content validities which were subjective participants' thoughts about the models. None of the studies explored the criteria that would objectively determine the true effect of a prospective model on the surgical learning curve [17-22]. 


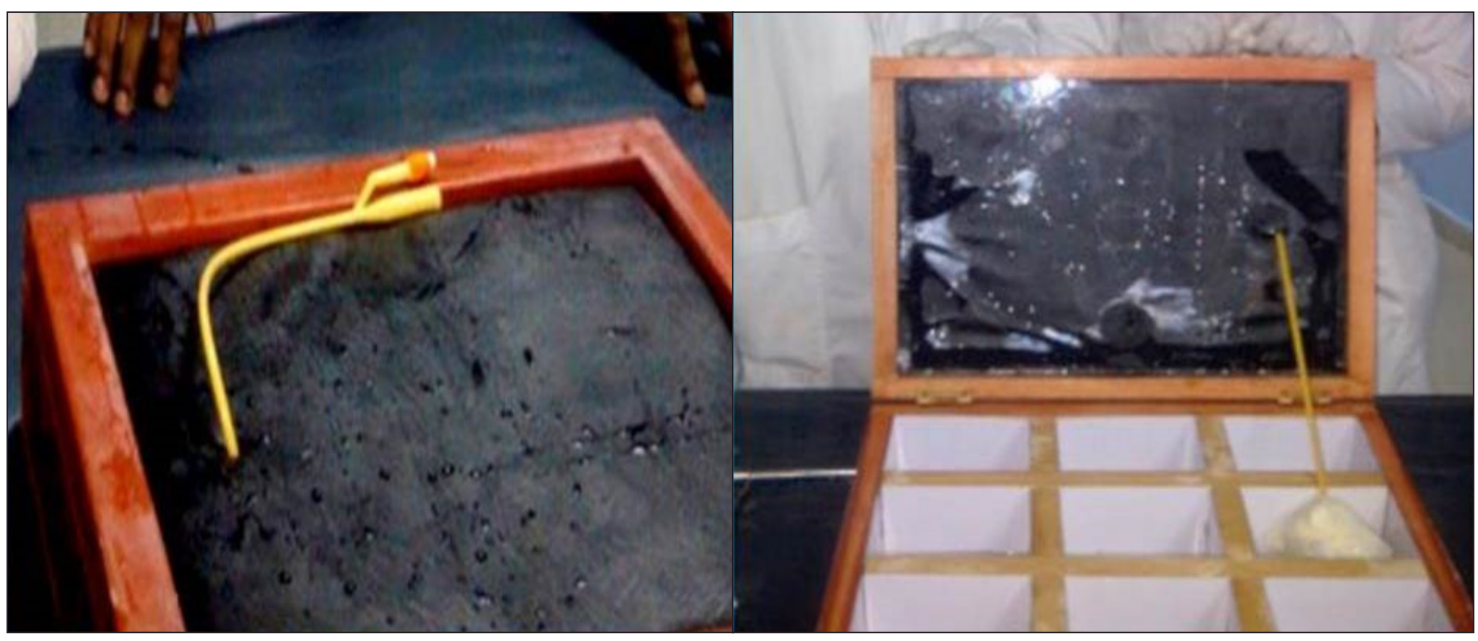

Fig. 4. The UCH bladder manikin simulation images (Image reproduced with courtesy of Creative Commons License: CC BY-NC-ND 4.0, available at: https://creativecommons.org/licenses/by-nc-nd/4.0/\#).

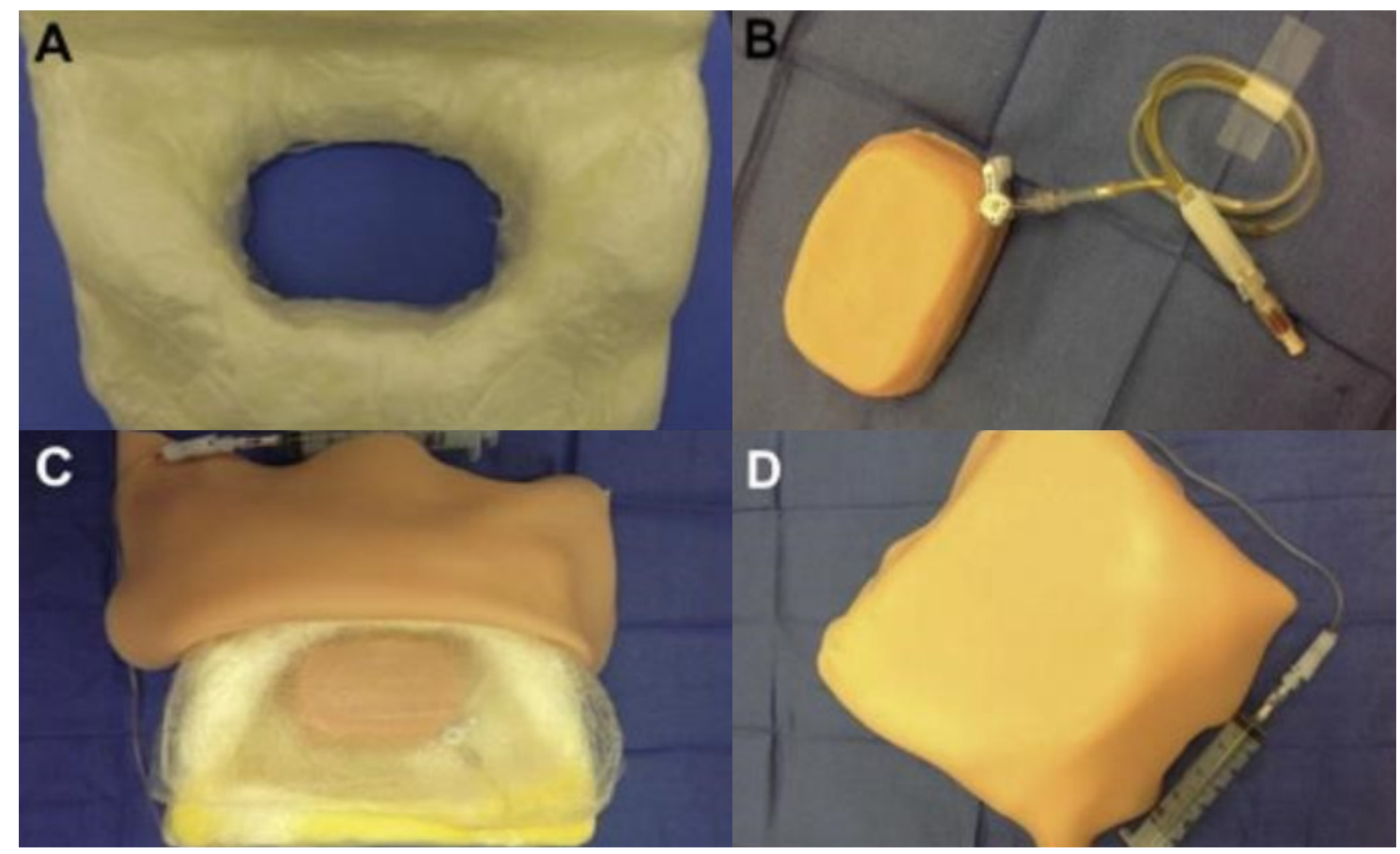

Fig. 5. The Singal et al. Training Model for suprapubic catheter insertion, construction images (Image reproduced with courtesy of publisher: Elsevier, with permission certificate number: 4302060520603, date of certificate: Mar 04, 2018).

Validated Simulator Models Reviewed

The UroEmerge ${ }^{\mathrm{TM}}$ (fig. 2) increased participants' ability to perform SPC insertion initially. However, over time participants' ability appeared to wane at 3 months post-course [17]. This model was the first ever (in the reviewed literature) to be described. It had a higher number of participants but neither their level of training nor prior successful real-life SPC insertions were specified. 


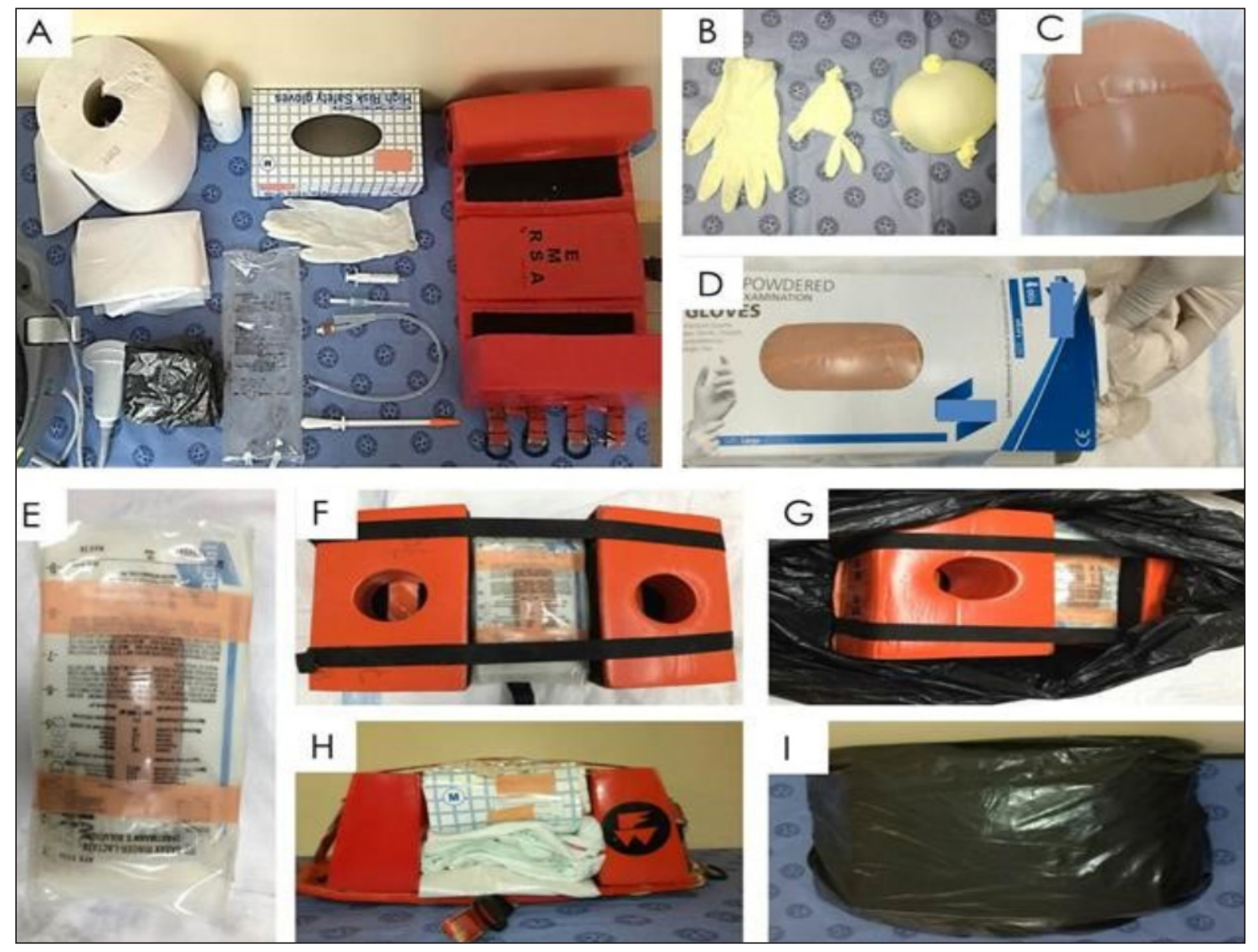

Fig. 6. A-I Construction outline pictures of the US-SCIT model. (Image reproduced with courtesy of publisher: Elsevier, with permission certificate number: 4302061109913, date of certificate: Mar 04, 2018).

Validation was by blind technique and confirmation of correct placement was by exposing the bladder at the end of the procedure. The model's ultrasound compatibility and costs were unspecified.

Hossack's 'lunch-box' model (fig. 3) was effective cost and easily reproducible. It had an initial running cost of 16.27 US\$ per trainee. Two of its major components were reusable, making consecutive runs cheaper [18]. It had the advantage of pre-prepared components enabling rapid resetting of units thus needing only 1 consultant to manage the entire course. However, validation was also made by blind technique, which is no longer recommended.

The bladder manikin (fig. 4) was an effective-low-cost aid in teaching SPC insertion [19]. This model required manufacturing prior to use. Validation was also by blind technique with unspecified participants' level of experience. The model's ultrasound compatibility and cost implications were unspecified.
Singal's model (fig. 5) was evaluated by 25 general surgeons and 6 'experts'. The initial material cost was 31.28 US\$. The 25 general surgeons had no prior SPC experience [20]. The model's US compatibility was unspecified, and validation was made by blind technique.

At 60.0 US\$ material cost, the VesEcho Training System was the most costly and had fewer numbers of evaluators. However, the model could withstand multiple needle punctures and be reused up to 10 times [21]. Further, it was ultrasound compatible and appeared to have the well-defined sonographic image display. Confirmation of correct catheter placement was made by visualization of intravesical trocar needle tip by ultrasound.

The ultrasound-guided suprapubic catheter insertion trainer (US-SCIT) (fig. 6,7) had the highest number of overall participants, was ultrasound compatible and the lowest material cost. It could be made from using materials found in most basic emergency departments within a 

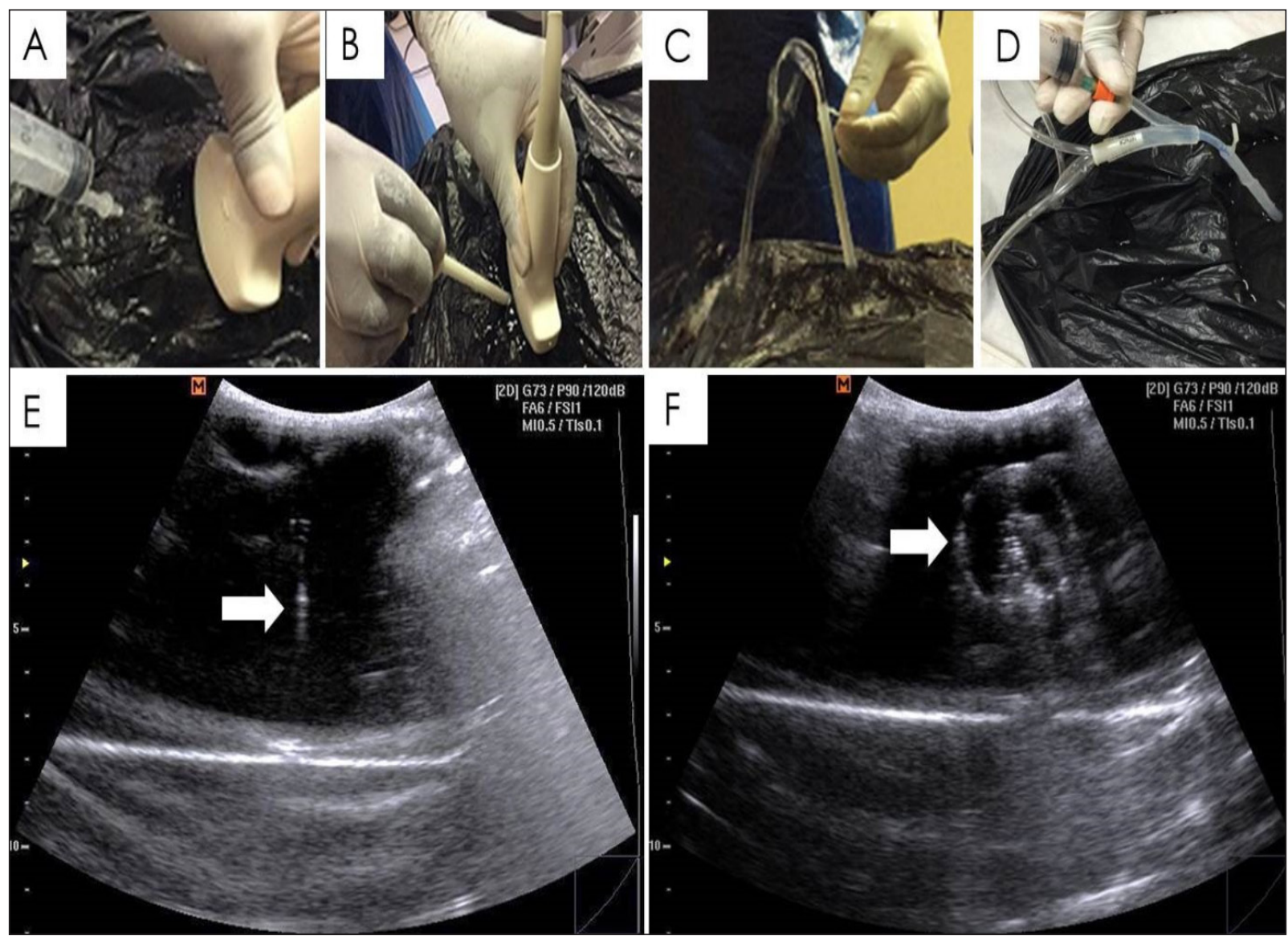

Fig. 7. Corresponding Ultrasound images of the US-SCIT in use. (Image reproduced with courtesy of publisher: Elsevier, with permission certificate number: 4302061109913, date of certificate: Mar 04, 2018).

short time [22]. However, the 1.71 US $\$$ cost did not include that of the head blocks which formed part of the entire unit. Like the VesEcho training system, confirmation of correct placement was by real-time ultrasonographic visualization of both the intravesical trocar needle tip and the inflated catheter balloon.

\section{SBME in Urological Training}

Although the optimal learning curve to achieve competence and proficiency in urological procedures may vary between individuals, a minimum case number for proficiency should be established by the relevant authorizing agencies [23]. There is a trend for the teaching of various surgical and procedural skills to move away from the operating room, to a controlled simulated laboratory environment $[24,25]$. Centralized simulation programs that seek to assist with the technical and non-technical aspects of urological training are feasible to improve overall outcomes and patient safety [26]. Among the fundamentals of establishing a simulation program, the concept of the 'P's of the marketing mix the place, people, pounds, products, program and positioning must be considered [27]. The 'pounds' factor pertains to costing of the actual simulation, which is a factor emphasized in the low cost models [26].

\section{Conclusion}

There is general paucity of development and validation of models utilized in the training of SPC insertion. At present, the various SPC simulators assessed within this review are a reasonable teaching adjunct, which can 
be implemented in (training) academic centers. Though SBME may not be the total replacement for the real-life patient-doctor interaction, it is a safe and efficient way to impart proficiency in fundamental surgical skills.

Developers of new SPC models must take into consideration the cost implications for their respective target market and the benefit of incorporating the use of ultrasound compatibility models in this scenario.

The use of SPC simulators would contribute to a successful SBME program, which in turn needs to be incorporated into the training curriculum for both urology and emergency department trainees across the globe.

\section{References}

-1 Ramos-Fernandez MR, Medero-Colon R, Mendez-Carreno L: Critical urologic skills and procedures in the emergency department. Emerg Med Clin North Am 2013;31:237-260.

-2 Preece R: The current role of simulation in urological training. Cent European J Urol 2015;68:207-211.

-3 Robinson AJ, Miller G, Rukin N: Simulation in urological training: where are we in 2017; J Clin Urol 2017;10:548-556.

$\checkmark 4$ Harrison SC, Lawrence WT, Morley R, Pearce I, Taylor J: British Association of Urological Surgeons' suprapubic catheter practice guidelines. BJU Int 2011;107:77-85.

$>5$ Brewin J, Ahmed K, Challacombe B: An update and review of simulation in urological training. Int J Surg 2014;12:103-108.

$>6$ Nyman MA, Schwenk NM, Silverstein MD: Management of urinary retention: rapid versus gradual decompression and risk of complications. Mayo Clin Proc 1997;72:951-956.

$>7$ Ahluwalia RS, Johal N, Kouriefs C, Kooiman G, Montgomery BS, Plail RO: The surgical risk of suprapubic catheter insertion and long-term sequelae. Ann R Coll Surg Engl 2006;88:210-213.

$>8$ Sheriff MK, Foley S, McFarlane J, Nauth-Misir R, Craggs M, Shah PJ: Long-term suprapubic catheterisation: clinical outcome and satisfaction survey. Spinal Cord 1998; 36:171-176.

-9 Jacob P, Rai BP, Todd AW: Suprapubic catheter insertion using an ultrasound-guided technique and literature review. BJU Int 2012; 110:779-784.
10 Shah PN, Chaskar VP, Rathod P, Komawar A, Gadpale B: Need of ultrasound in emergency department for suprapubic catheterization. Int J Anesthetic Anesthesiol 2014;1:14.

11 Schout BM, Hendrikx AJ, Scheele F, Bemelmans BL, Scherpbier AJ: Validation and implementation of surgical simulators: a critical review of present, past, and future. Surg Endosc 2010;24:536-546.

12 Prystowsky JB, Regehr G, Rogers DA, Loan JP, Hiemenz LL, Smith KM: A virtual reality model for intravenous catheter placement. Am J Surg 1999;177:171-175.

$\checkmark 13$ McDougall EM: Validation of surgical simulators. J Endourol 2007;21:244-247.

14 Moher D, Shamseer L, Clarke M, Ghersi D, Liberati A, Petticrew M, Shekelle P, Stewart LA: Preferred reporting items for systematic review and meta-analysis protocols (PRISMA-P) 2015 statement. Syst Rev 2015;4:1.

15 Critical Appraisal Skills Programme. CASP Checklist 2018. Available online at: www. casp-uk.net. Accessed on 1st April, 2018.

16 Rosen KR: The history of medical simulation. J Crit Care 2008;23:157-166.

17 Shergill IS, Shaikh T, Arya M, Junaid I: A training model for suprapubic catheter insertion: the UroEmergeTM suprapubic catheter model. Urology 2008;72:196-197.

18 Hossack T, Chris B, Beer J, Thompson G: A cost-effective, easily reproducible, suprapubic catheter insertion simulation training model. Urology 2013;82:955-958.

19 Olapade-Olaopa EO, Adebayo SA, Chibuzo IN, Takure AO, Okeke LI, Shittu OB: The UCH bladder manikin - a locally designed teaching aid for suprapubic catheterization in low-resource countries. Afr J Urol 2015; 21:262-265.
20 Singal A, Halverson A, Rooney DM, Davis LM, Kielb SJ: A validated low-cost training model for suprapubic catheter insertion. Urology 2015;85:23-26.

21 Palvolgyi R, Lee A, Ramirez F, Durbin-Johnson B, Rothschild J, Yang J: VesEcho training system: suprapubic catheterization under ultrasound guidance. Urol Pract 2018;5:63-68.

22 Nonde J, Adam A, Laher AE: Validation of a low cost, disposable, and ultrasound-guided suprapubic catheter insertion trainer. Urology 2018;115:45-50.

-23 Abboudi H, Khan MS, Guru KA, Froghi S, de Win G, Van Poppel H, Dasgupta P, Ahmed $\mathrm{K}$ : Learning curves for urological procedures: a systematic review. BJU Int 2014; 114:617-629.

24 De Montbrun SL, Macrae H: Simulation in surgical education. Clin Colon Rectal Surg 2012;25:156-165.

25 Schout BM, Hendrikx AJ, Scherpbier AJ, Bemelmans BL: Update on training models in endourology : a qualitative systematic review of the literature between January 1980 and April 2008. Eur Urol 2008;54:1247-1261.

26 Shamim Khan M, Ahmed K, Gavazzi A, Gohil R, Thomas L, Poulsen J, Ahmed M, Jaye P, Dasgupta P: Development and implementation of centralized simulation training: evaluation of feasibility, acceptability and construct validity. BJU Int 2013;111:518-523.

$\checkmark 27$ Ahmed K, Amer T, Challacombe B, Jaye P, Dasgupta P, Khan MS: How to develop a simulation programme in urology. BJU Int 2011; 108:1698-1072. 